\title{
Integrating E-Prescribing and Pharmacy Claims Data for Predictive Modeling: Comparing Costs and Utilization of Health Plan Members Who Fill Their Initial Medications with Those Who Do Not
}

\author{
Hsien-Yen Chang, PhD; Hong J. Kan, PhD; Kenneth M. Shermock, PharmD, PhD; \\ G. Caleb Alexander, MD, MSc; Jonathan P. Weiner, DrPH; and Hadi Kharrazi, MD, PhD
}

\begin{abstract}
BACKGROUND: Nonfilling of prescribed medications is a worldwide problem of serious concern. Studies of health care costs and utilization associated with medication nonadherence frequently rely on claims data and usually focus on patients with specific conditions. Past studies also have little agreement on whether higher medication costs associated with higher adherence can reduce downstream health care consumption.
\end{abstract}

OBJECTIVES: To (a) compare the characteristics between people with and without complete medication initiations from a general population and (b) quantify the effect of medication initiation on health care utilization and expenditures with propensity score weighting.

METHODS: We conducted a retrospective cohort study using 2012 and 2013 electronic health records (EHR) and insurance claims data from an integrated health care delivery network. We included 43,097 eligible primary care patients in the study. Annual medication fill rates of initial prescriptions in 2012 were defined as the number of filled prescriptions from claims divided by the number of e-prescriptions from EHRs, while excluding all refills. A claim was considered filled if (a) EHR and claims records were from the same drug class; (b) claims occurred between the date of a current EHR order and that of the next EHR order of the same class; and (c) the maximum fill rate was $100 \%$. The 6 annual outcomes included total costs, medical costs, pharmacy costs, being a high-cost "outlier" (in top 5\%), having 1 or more hospitalizations, and having 1 or more emergency department (ED) visits. Individuals were classified as either having completed all medication initiations ( $100 \%$ annual filling rate for initiations) or not. We used propensity score weighting to control for baseline differences between complete and incomplete initial fillers. We adopted linear and logistic regressions to model costs and binary utilization indicators for the same year (concurrently) and next year (prospectively).

RESULTS: Approximately $42 \%$ of the study sample had complete medication initiations ( $100 \%$ filling rate), while the remaining $58 \%$ had incomplete initiations. Individuals who fully filled initial prescriptions had lower comorbidity burden and consumed fewer health care resources. After applying propensity score weighting and controlling for variables such as the number of prescription orders, patients with complete medication initiations had lower overall and medical costs, concurrently and prospectively (e.g., \$751 and \$252 less for annual total costs). Complete medication initiation fillers were also less likely to have concurrent health care utilization $(\mathrm{OR}=0.78,95 \% \mathrm{Cl}=\mathbf{0 . 6 8}-0.90$ for hospitalization; $\mathrm{OR}=0.77$, $95 \% \mathrm{Cl}=0.72-0.82$ for $\mathrm{ED}$ admissions) but no difference in prospective utilization other than for $\mathrm{ED}$ visits $(\mathrm{OR}=0.93,95 \% \mathrm{Cl}=0.87-0.99)$.

CONCLUSIONS: Identifying the subpopulation of patients with incomplete medication initiations (i.e., filling less than $100 \%$ of initial prescriptions) is a pragmatic approach for population health management programs to align resources and potentially contain cost and utilization.

J Manag Care Spec Pharm. 2020;26(10):1282-90

Copyright $\odot 2020$, Academy of Managed Care Pharmacy. All rights reserved.

\section{What is already known about this subject}

Lack of filling prescriptions is a worldwide problem of serious concern and cost the American health care system annually between $\$ 100$ and $\$ 289$ billion in the 2000s.

Past studies measuring the cost of nonfilling medications have little agreement on whether higher medication costs associated with higher adherence can reduce downstream health care expenditures.

\section{What this study adds}

After propensity score weighting and covariate adjustment, complete medication initiations (i.e., filling all initial prescriptions) were associated with lower health care costs concurrently and prospectively.

After propensity score weighting and covariate adjustment, complete medication initiations were associated with lower likelihood of health care utilization concurrently and lower likelihood of having any emergency department visits prospectively.

$\mathrm{N}$ onfilling of prescribed medications is a worldwide problem of serious concern. The World Health Organization estimates the adherence to long-term therapy for chronic diseases at only 50\% in developed countries, including the United States, and even lower rates in developing countries. ${ }^{1,2}$ Nonadherence leads to poor health outcomes and increased costs. ${ }^{1}$ It is estimated that 20\%-30\% of U.S. prescriptions never get filled and that the lack of filling prescriptions caused about 125,000 deaths and cost the American health care system between $\$ 100$ and $\$ 289$ billion per year in the 2000s. ${ }^{3}$ A more recent study estimates that the annual cost of prescription drug-related morbidity and mortality because of nonoptimized medication therapy, including medication nonadherence, was $\$ 528.4$ billion in $2016 .^{4}$

Past studies have estimated the cost and health care utilization associated with nonfilled medications. One study estimated that among patients with cystic fibrosis, compared with patients with a high composite medication possession ratio (MPR), those with low and moderate MPR were associated with higher concurrent medical costs $(\$ 14,211$ and $\$ 8,493)$ 
and more hospitalizations. ${ }^{5}$ Another study found that higher medication adherence significantly reduces annual costs for secondary prevention of coronary artery disease (between $\$ 294$ and $\$ 868$ per patient $\left.{ }^{6}\right)$. One study found that medication nonadherence was associated with $37 \%$ lower pharmacy costs, $7 \%$ lower outpatient costs, and $41 \%$ higher inpatient costs among patients with diabetes. ${ }^{7}$ A review of the literature concluded that higher medication adherence among patients with diabetes was associated with improved glycemic control, fewer emergency department (ED) visits, decreased hospitalizations, and lower medical costs. ${ }^{8}$ Another review suggested that higher adherence to biologics among patients with rheumatoid arthritis was associated with lower total nonpharmacy costs and health care utilization, but higher pharmacy costs. ${ }^{9}$

Despite their findings, past studies measuring the costs of nonfilled medications have little agreement on whether higher medication costs associated with higher adherence can reduce downstream health care expenditures. ${ }^{10}$ Moreover, studies have frequently focused on patients with a specific chronic condition, ${ }^{5-7,10-16}$ making them inconclusive for comorbidities on a population level. Past studies have also often adjusted for confounding by including covariates as regressors in multivariate models, $, 6,7,12,14-16$ thus, lacking the application of more rigorous methods such as propensity score matching. Additionally, these studies have derived measures of adherence and health care costs and utilization from the same period, , $, 10,12-16$ therefore, providing insufficient evidence on the effect of nonfilled medication initiations on prospective health care utilization. Finally, these studies have often used measures of nonadherence, such as MPR or proportion of days covered (PDC), that cannot be easily aggregated to the individual level and targeted by population health management programs and interventions. ${ }^{10}$

We assessed the effect of complete medication initiation (patients filling all of the initial prescriptions (complete initiation) versus those who did not fill 1 or more such initial prescriptions (incomplete initiation) on health care costs and utilization. In assessing such effect, we controlled for potential confounding factors by propensity score weighting and by considering the number of medications the clinician ordered.

\section{Methods}

\section{Data Source}

We used e-prescribing information found within electronic health records (EHRs) and medical and pharmacy claims data provided by HealthPartners health care delivery network. Located in Minnesota and with more than 1.5 million health plan enrollees, HealthPartners is a multispecialty group consisting of more than 1,700 physicians practicing in 7 hospitals, 47 primary care clinics, and 22 urgent care facilities. HealthPartners' services include medical care delivery and health plan financing. EHR data provided by HealthPartners captured complete outpatient information occurring within its care groups but not outside.

We excluded inpatient EHR encounters from the analysis, since inpatient data were determined as partial in a past study. ${ }^{17,18}$ EHR and claims data contained demographics (age and sex), diagnosis codes documented as International Classification of Diseases, Ninth Revision, Clinical Modification (ICD-9-CM) codes, prescriptions as National Drug Code (NDC) numbers, days of the prescription supplied, and dates of services. Dates were used to ascertain the temporality of prescription orders extracted from EHR and prescriptions fills from claims. Paid amount by plan and out-of-pocket amount by individuals were derived from administrative claims. An indicator for refill prescriptions (i.e., medication initiation vs noninitiation) was also available from EHR data.

\section{Study Design and Subject}

This study was a 2-year retrospective cohort study (2012-2013). Independent variables were constructed from 2012 data, while outcome variables were derived from 2012 and 2013 data. Our initial population included 141,716 members with continuous medical enrollment and at least 1 physician visit over the 2-year study period. We included 43,097 eligible members in our study after excluding the following: (a) 629 members with data quality issues (e.g., mismatching age or sex between EHR and claims), newborns, and pregnant/delivered women; (b) 4,369 elderly members, as we had no Medicare claims; (c) 64,736 patients without any ordered prescriptions or with "as needed" or "over-the-counter" prescriptions only; and (d) 28,885 members without complete pharmacy enrollment (Figure 1). This study was approved by the Institutional Review Board of the Johns Hopkins University (IRB \#00005784).

\section{Complete Versus Incomplete Medication Initiations}

We calculated medication initiation filling rates (as a continuous variable ranging between $0 \%$ to 100\%) for all individuals in 2012 using the method defined in a previous study and adopted from the EMERGE framework. ${ }^{17,19}$ An individual's annual medication initiation filling rate was calculated as the number of filled records from claims divided by the number of medication initiations from EHR in 2012. A claims record was considered a filled record if (a) EHR and claims records were assigned to the same RxMG (pharmacy-based morbidity group), a broad condition-related medication classification system developed as part of the Johns Hopkins Adjusted Clinical Group (ACG) System; (b) claims occurred between the date of a current EHR order and the date of the next EHR order of the same RxMG; and (c) the number of filled claims records did not exceed the number of EHR orders (i.e., the maximum fill rate was 100\%). We did not use NDC numbers as the basis for "filling" because pharmacists may substitute a drug with another similar medication. We restricted our main analysis to 


\section{FIGURE 1 Study Sample Flowchart}

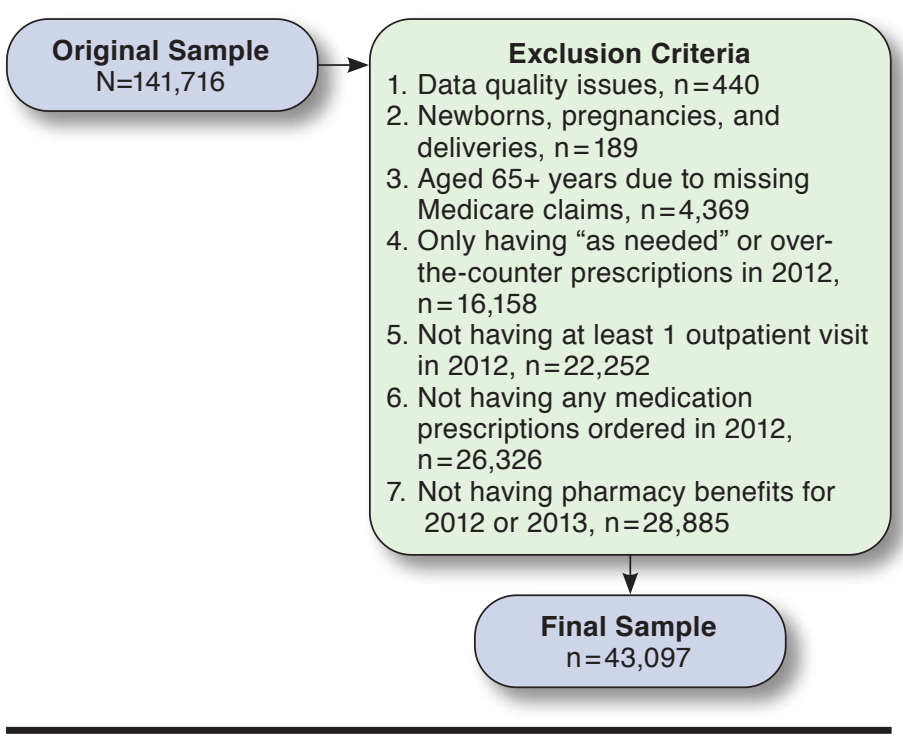

prescriptions filled within 7 days of a given order, although in the sensitivity analysis we relaxed this restriction to prescriptions filled within 30 days of a given order.

As a pragmatic measure for risk stratification and because of the distribution of medication initiation rates across the population, we classified patients into 2 groups: with complete medication initiations (100\% filling rate of initiations) and with incomplete medication initiations (less than 100\% filling rate of initiations). Complete initiations were set at $100 \%$, since the spread of medication initiation filling rates was highly skewed (i.e., $42 \%$ of the total population were identified as having $100 \%$ filling rate and relaxing the percentage to $75 \%$ of the filling rates only increased the subpopulation by $9 \%$ ). Additionally, the split of $100 \%$ versus less than 100\% filling of initial prescriptions improved the performance of propensity score weighting as the standardized difference becomes smaller within each subpopulation (described in the following section).

\section{Outcome Variables}

We examined 3 types of costs (i.e., total costs, medical costs, and pharmacy costs) and 3 binary utilization indicators (i.e., users in top $5 \%$ of total cost, having $\geq 1$ hospitalization, and having $\geq 1$ ED visits). All types of costs were truncated at top $0.5 \%$ of positive costs to reduce the effect of outliers on the results. ${ }^{17,20}$ The outcomes were derived from either the concurrent (2012) or the prospective (2013) periods. All outcomes were extracted from claims data only, which represented complete health care costs and utilizations across all providers and settings (inpatient and outpatient).

\section{Control Variables}

Using medical and pharmacy claims as inputs, control variables were derived from the Johns Hopkins Adjusted Clinical Group (ACG v11.0) Risk Adjustment System. ${ }^{21-23}$ The ACG system assigns all ICD codes to 1 of 32 binary Aggregated Diagnostic Clusters (ADGs) based on the expected need for medical resources and also assigns all NDC numbers to 1 of 67 dichotomous RxMGs based on the combination of active ingredients and route of administration. Expanded Diagnosis Clusters (EDCs) are binary indicators for specific diseases/ symptoms based on diagnostic codes. The ACG system also generates a risk score for concurrent total costs, including independent variables such as an overall diagnoses-based disease burden, high-impact chronic conditions, diagnoses representing a high likelihood of hospitalization, and acute conditions. The ACG system is widely used for measuring morbidity, ${ }^{18,22-27}$ and it has been validated against costs, ${ }^{25,26,28}$ utilization, ${ }^{21,28-31}$ and death. ${ }^{32}$ We also included the number of prescribed orders as a control variable in the model (truncated at 30), since patients with fewer prescribed orders are more likely to have complete medication initiations. Costs were not included as control variables in this study.

\section{Statistical Analysis}

In the statistical analysis, we described the characteristics of subpopulations with complete and incomplete medication initiations. We used the t-test to compare the differences between complete and incomplete medication initiations for continuous and count variables and used the chi-square test for categorical or binary variables.

Then, we built statistical models to evaluate the effect of having complete medication initiations on health care costs and utilization. To control for baseline differences in patient characteristics between complete and incomplete medication initiations, we calculated a propensity score for each individual; among various applications of propensity score, we chose propensity score weighting. This method has been adopted and validated in past studies. ${ }^{33-35}$ Propensity score weighting allowed us to include all members of our cohort, which would not likely occur with standard matching, and provided interpretable overall estimates, which is also not feasible to generate with traditional stratification methods.

We applied logistic regression to obtain an individual's propensity score of becoming a complete medication initiator based on sex, age categories $(0-4,5-11,12-17,18-34,35-44$, and 45-54 years), 32 diagnosis-based ADGs, 67 medicationbased RxMGs, and the number of prescribed orders. Using the predicted probabilities derived from such models, we calculated an average treatment effect of the treated (ATT) propensity score weighting. Through ATT, we estimated the average effect of treatment on the treated subjects, thus, making comparisons between the actual outcomes of patients with 


\begin{tabular}{|c|c|c|c|}
\hline TABLE 1 & $\begin{array}{l}\text { Characterist } \\
\text { Utilization o } \\
\text { Medication }\end{array}$ & $\begin{array}{l}\text { Health } \mathrm{C} \\
\text { Health Plan } \\
\text { tiation Stat }\end{array}$ & $\begin{array}{l}\text { Costs, and } \\
\text { tients by } \\
2012\end{array}$ \\
\hline & $\begin{array}{l}\text { Complete } \\
\text { Medication } \\
\text { Initiations }\end{array}$ & $\begin{array}{l}\text { Incomplete } \\
\text { Medication } \\
\text { Initiations }\end{array}$ & $\begin{array}{l}\text { Total } \\
\text { Cohort }\end{array}$ \\
\hline Study population, $\mathrm{n}$ & 24,991 & 18,106 & 43,097 \\
\hline Female, \% & 62.55 & 62.31 & 62.45 \\
\hline Age, yeara & $43.0 \quad(15.9)$ & $39.3 \quad(17.5)$ & $41.48 \quad(16.70)$ \\
\hline ADGs, count ${ }^{\mathrm{a}}$ & $6.7 \quad(3.5)$ & $(3.1)$ & $6.30 \quad(3.33)$ \\
\hline EDCs, count $^{\mathrm{a}}$ & $(6.2)$ & $(4.9)$ & $8.72 \quad(5.80)$ \\
\hline RxMGs, count ${ }^{\mathrm{a}}$ & $4.5 \quad(3.1)$ & $3.6 \quad(2.4)$ & $4.14 \quad(2.84)$ \\
\hline $\begin{array}{l}\text { Chronic conditions, } \\
\text { count }^{\mathrm{a}}\end{array}$ & $1.84 \quad(1.84)$ & $1.16 \quad(1.38)$ & $1.56 \quad(1.70)$ \\
\hline $\begin{array}{l}\text { Active ingredients, } \\
\text { count }^{\mathrm{a}}\end{array}$ & $(4.8)$ & $(3.5)$ & $(4.39)$ \\
\hline Pharmacy cost, $\$ a$ & $1,747 \quad(4,564)$ & $1,024 \quad(3,348)$ & $1,443 \quad(4,113)$ \\
\hline Medical cost, $\$$ a & $8,525(21,918)$ & $3,897(12,057)$ & $6,581(18,570)$ \\
\hline Total cost, $\$ \mathrm{a}$ & $10,271(23,110)$ & $4,922(12,941)$ & $8,024(19,673)$ \\
\hline IP visit, count ${ }^{\mathrm{a}}$ & $0.10 \quad(0.41)$ & $0.03 \quad(0.20)$ & $0.07 \quad(0.34)$ \\
\hline $\begin{array}{l}\text { Emergency visit, } \\
\text { count }^{\mathrm{a}}\end{array}$ & $0.23 \quad(0.65)$ & $0.13 \quad(0.47)$ & $(0.58)$ \\
\hline Any IP, \%a & 7.75 & 2.24 & 5.44 \\
\hline $\begin{array}{l}\text { Any readmission, } \\
\%^{\mathrm{a}}\end{array}$ & 0.79 & 0.18 & 0.53 \\
\hline $\begin{array}{l}\text { Any emergency } \\
\text { visit, \% }{ }^{\mathrm{a}}\end{array}$ & 16.62 & 10.79 & 14.17 \\
\hline \multicolumn{4}{|c|}{$\begin{array}{l}\text { Note: All results are shown as mean (SD), unless indicated otherwise. } \\
\text { aP }<0.01 \text {. } \\
\text { ADG }=\text { Aggregated Diagnostic Clusters; EDCs = Expanded Diagnosis Clusters; } \\
\text { IP = inpatient; } R x M G S=R x \text {-Defined Morbidity Groups. }\end{array}$} \\
\hline
\end{tabular}

complete medication initiations and the expected outcomes under the counterfactual assumption if they had incomplete medication initiations. ${ }^{36}$ After applying propensity score ATT weighting, the absolute standardized differences of all variables in the propensity score models reduced to less than 0.1, suggesting negligible differences between the 2 groups. ${ }^{36}$

To analyze outcomes, we adopted linear regression to model costs, since it is widely used to analyze costs, delivers intuitive results, and often performs similar to advanced models in predicting costs. ${ }^{25,37}$ We applied logistic regression for binary utilization indicators. For each outcome, we built 4 models with various sets of control variables and the adoption of ATT weighting. Within these models, we reported the coefficients associated with a binary indicator of being a complete medication initiator, which is the main independent variable. The control variables in these models were (a) the number of prescribed orders; (b) model 1 plus ATT weighting; (c) age groups, sex, an ACG risk score, and the number of prescribed orders; and (d) model \#3 plus ATT weighting.

\section{Results}

\section{Characteristics of the Study Sample}

Approximately $42 \%$ of the study sample had complete medication initiations, while the remaining 58\% had incomplete initiations. Differences in the characteristics between patients with complete and incomplete medication initiations were statistically significant across all variables except gender (i.e., $\sim 60 \%$ of either group was female; Table 1). The "complete medication initiation" cohort was slightly younger (i.e., aged 39 years vs. 43 years), had lower morbidity burden (e.g., count of chronic conditions: 1.16 vs. 1.84; count of active ingredients: 4.7 vs. 6.0; count of ADGs: 5.7 vs. 6.7), experienced lower health care costs (i.e., total costs: $\$ 4,922$ annually vs. $\$ 10,271$ ), and had lower health care utilization (e.g., any hospitalization: $2.24 \%$ vs. 7.75\%; any emergency visit: $10.8 \%$ vs. $16.6 \%$; Table 1).

\section{Health Care Costs Associated with Having Complete Medication Initiations}

In the concurrent analysis, having complete medication initiations was associated with statistically significantly lower total and medical costs across all models, with the exception of pharmacy costs (Table 2, concurrent analysis). For example, in the most comprehensive model (model 4), having complete medication initiation was statistically significantly associated with a $\$ 751$ (95\% CI=\$613-\$889) reduction in concurrent total costs and a $\$ 775(95 \% \mathrm{CI}=\$ 648-\$ 908)$ reduction in concurrent medical costs, with no change in pharmacy costs.

In the prospective analysis, having complete medication initiations was associated with statistically significantly lower costs (medical and total) across all models with ATT weighting, with the exception of pharmacy costs (Table 2, prospective analysis). For example, in model 4, having complete medication initiations was statistically significantly associated with a $\$ 252$ (95\% CI $=\$ 54-\$ 451)$ reduction in prospective total costs and a $\$ 221$ (95\% CI $=\$ 36-\$ 407)$ reduction in prospective medical costs, with no statistically significant change in pharmacy costs.

\section{Health Care Utilization Associated with Having Complete Medication Initiations}

In the concurrent analysis, having complete medication initiations was associated with statistically significantly lower likelihood of having any utilization outcome across all models (Table 3, concurrent analysis). For example, in the most comprehensive model (model 4), patients with complete medication initiations were statistically significantly less likely to have any hospitalization (odds ratio $[\mathrm{OR}]=0.783,95 \% \mathrm{CI}=0.680-0.902$ ), have any emergency visit $(\mathrm{OR}=0.766,95 \% \mathrm{CI}=0.717-0.818)$, or become a top $5 \%$ user $(\mathrm{OR}=0.766,95 \% \mathrm{CI}=0.679-0.864)$.

In the prospective analysis, having complete medication initiations was only associated with statistically significantly lower likelihood of having any emergency visit in models with ATT weighting, but not the other 2 outcomes (Table 3, 
TABLE 2 Incremental Differences in Health Care Costs Associated with Complete Medication Initiations by Different Adjustment Models

\begin{tabular}{|c|c|c|c|c|c|c|}
\hline & \multicolumn{3}{|c|}{ Concurrent Analysis } & \multicolumn{3}{|c|}{ Prospective Analysis } \\
\hline & $\begin{array}{l}\text { Total Cost } \\
\$(95 \% \mathrm{CI})\end{array}$ & $\begin{array}{l}\text { Medical Cost } \\
\$(95 \% \mathrm{CI})\end{array}$ & $\begin{array}{l}\text { Pharmacy Cost } \\
\$(95 \% \mathrm{CI})\end{array}$ & $\begin{array}{l}\text { Total Cost } \\
\$(95 \% \mathrm{CI})\end{array}$ & $\begin{array}{l}\text { Medical Cost } \\
\$(95 \% \mathrm{CI})\end{array}$ & $\begin{array}{l}\text { Pharmacy Cost } \\
\$(95 \% \mathrm{CI})\end{array}$ \\
\hline $\begin{array}{l}\text { Model 1: Complete initiation + number of } \\
\text { orders }\end{array}$ & $\begin{array}{c}-574 a \\
(-809,-339)\end{array}$ & $\begin{array}{c}-671^{\mathrm{a}} \\
(-891,-451) \\
\end{array}$ & $\begin{array}{c}99 a \\
(38,159)\end{array}$ & $\begin{array}{c}74 \\
(-194,341)\end{array}$ & $\begin{array}{c}10 \\
(-232,251) \\
\end{array}$ & $\begin{array}{c}47 \\
(-23,118) \\
\end{array}$ \\
\hline $\begin{array}{l}\text { Model 2: Complete initiation + number of } \\
\text { orders + PS weighting }\end{array}$ & $\begin{array}{c}-824^{\mathrm{a}} \\
(-1,005,-643)\end{array}$ & $\begin{array}{c}-830^{\mathrm{a}} \\
(-993,-668)\end{array}$ & $\begin{array}{c}-17 \\
(-66,32)\end{array}$ & $\begin{array}{c}-335^{\mathrm{a}} \\
(-557,-112)\end{array}$ & $\begin{array}{c}-282^{\mathrm{a}} \\
(-481,-83)\end{array}$ & $\begin{array}{c}-57 \\
(-114,1)\end{array}$ \\
\hline $\begin{array}{l}\text { Model 3: Complete initiation + number of } \\
\text { orders + age + sex + DxRx PM score }\end{array}$ & $\begin{array}{c}-827^{\mathrm{a}} \\
(-1,016,-637)\end{array}$ & $\begin{array}{c}-888^{a} \\
(-1,076,-700)\end{array}$ & $\begin{array}{c}64 \mathrm{~b} \\
(8,120)\end{array}$ & $\begin{array}{c}-74 \\
(-313,165)\end{array}$ & $\begin{array}{c}-96 \\
(-320,127)\end{array}$ & $\begin{array}{c}11 \\
(-55,77)\end{array}$ \\
\hline $\begin{array}{l}\text { Model 4: Complete initiation + number of } \\
\text { orders + age + sex + DxRx PM score + PS weighting }\end{array}$ & $\begin{array}{c}-751^{\mathrm{a}} \\
(-889,-613)\end{array}$ & $\begin{array}{c}-775^{\mathrm{a}} \\
(-908,-642)\end{array}$ & $\begin{array}{c}0 \\
(-43,43)\end{array}$ & $\begin{array}{c}-252^{b} \\
(-451,-54)\end{array}$ & $\begin{array}{c}-221^{b} \\
(-407,-36)\end{array}$ & $\begin{array}{c}-38 \\
(-90,13)\end{array}$ \\
\hline
\end{tabular}

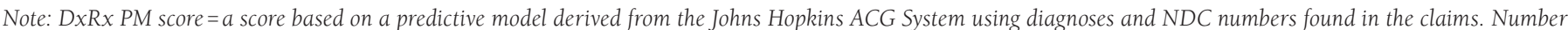
of orders = number of first-ordered e-prescriptions derived from the EHR during the year.

aP $<0.01$

${ }^{b} P<0.05$.

ACG=Adjusted Clinical Group; $C I=$ confidence interval; EHR=electronic health record; NDC=National Drug Code; PS=propensity score.

prospective analysis). For example, in model 4, patients with complete medication initiations were statistically significantly less likely to have any emergency visit ( $\mathrm{OR}=0.928,95 \%$ $\mathrm{CI}=0.868-0.993)$.

The results of the sensitivity analyses, using a 30-day threshold to define complete medication initiations, yielded similar findings and are reported in Supplementary Tables 1-3 (available in online article).

\section{Discussion}

Using 2 years of claims and EHR data from an integrated delivery network, we compared the characteristics between subpopulations with complete and incomplete medication initiations. We evaluated concurrent and prospective health care utilization and spending associated with having complete medication initiations. We found that compared with patients with incomplete medication initiations, complete initiators were younger, had less morbidity burden, and consumed less health care resources. After applying propensity score weighting and including control variables, having complete medication initiations was associated with lower total and medical costs, concurrently and prospectively (Table 2 ). In addition, patients with complete medication initiations were less likely to have health care utilization concurrently (i.e., hospitalization, ED admission, and being in the top 5\% of cost), but only less likely to have an emergency visit prospectively (Table 3).

We used the filling status of initial prescriptions as a pragmatic measure of medication nonadherence that can be operationalized in population health management setting. To choose a pragmatic measure of nonadherence, we decided to exclude measures that require the medication to be new and dropped measures that needed the complex calculations of refills. Thus, we chose completion of medication initiations instead of primary medication nonadherence (PMN), since PMN requires an extended retrospective inspection of data to ensure that the medication is new (i.e., first time the patient has received the medication in 24 months). Additionally, completion of medication initiations does not require the complex calculations of refills (often requiring mining the medication order instructions in EHRs and day-dose calculations) used in adherence measures such as MPR or PDC.

To make our measure more pragmatic, we split the population into patients with $100 \%$ completion of medication initiations (i.e., filling all nonrefill prescriptions) versus patients with less-than-100\% completion rates (i.e., incomplete medication initiations). Furthermore, we limited the time allowed to fill a medication (e.g., 7 or 30 days) to ensure ease of calculation and having meaningful predictions in operational settings (i.e., requiring a long period of 90 or 180 days to fill a medication defies the need for predicting health care utilization, since utilization is already observed in such data).

By design, a person with fewer first-order prescribed medications is more likely to have complete medication initiations; for example, a patient with just 1 initial prescribed medication was more likely to have complete medication initiations than someone with 10 initial prescribed medications because the former only needed to fill 1 while the latter had to fill all 10 orders to have all medication initiations completed/filled. Also, study results showed that patients with complete medication initiations had on average 2.1 prescribed orders, while patients with incomplete medication initiations had 5 orders (Table 1). Given that patients receiving fewer medications are more likely to have lower morbidity burden, it could be expected that patients with complete medication initiations consume fewer health care resources. 


\section{TABLE 3 Odds Ratio of Health Care Utilization Associated with Complete Medication Initiations by Different} Adjustment Models

\begin{tabular}{|c|c|c|c|c|c|c|}
\hline & \multicolumn{3}{|c|}{ Concurrent Analysis } & \multicolumn{3}{|c|}{ Prospective Analysis } \\
\hline & $\begin{array}{l}\text { Any IP } \\
(95 \% \mathrm{CI})\end{array}$ & $\begin{array}{l}\text { Any ED } \\
(95 \% \mathrm{CI})\end{array}$ & $\begin{array}{l}\text { Top } 5 \% \text { Users } \\
(95 \% \mathrm{CI})\end{array}$ & $\begin{array}{l}\text { Any IP } \\
(95 \% \mathrm{CI})\end{array}$ & $\begin{array}{l}\text { Any ED } \\
(95 \% \mathrm{CI})\end{array}$ & $\begin{array}{c}\text { Top } 5 \% \text { Users } \\
(95 \% \mathrm{CI})\end{array}$ \\
\hline $\begin{array}{l}\text { Model 1: Complete initiation + number of } \\
\text { orders }\end{array}$ & $\begin{array}{c}0.597 \mathrm{a} \\
(0.530,0.672)\end{array}$ & $\begin{array}{c}0.739 a \\
(0.695,0.786)\end{array}$ & $\begin{array}{c}0.663^{a} \\
(0.605,0.727)\end{array}$ & $\begin{array}{c}0.999 \\
(0.897,1.112)\end{array}$ & $\begin{array}{c}0.979 \\
(0.918,1.045)\end{array}$ & $\begin{array}{c}0.903^{b} \\
(0.828,0.985)\end{array}$ \\
\hline $\begin{array}{l}\text { Model 2: Complete initiation + number of } \\
\text { orders + PS weighting }\end{array}$ & $\begin{array}{c}0.770^{\mathrm{a}} \\
(0.674,0.880)\end{array}$ & $\begin{array}{c}0.775^{\mathrm{a}} \\
(0.727,0.826) \\
\end{array}$ & $\begin{array}{c}0.778^{\mathrm{a}} \\
(0.703,0.861)\end{array}$ & $\begin{array}{c}0.977 \\
(0.871,1.095)\end{array}$ & $\begin{array}{c}0.926^{b} \\
(0.866,0.990)\end{array}$ & $\begin{array}{c}0.884^{\mathrm{a}} \\
(0.806,0.970)\end{array}$ \\
\hline $\begin{array}{l}\text { Model 3: Complete initiation + number of } \\
\text { orders + age + sex + DxRx PM score }\end{array}$ & $\begin{array}{c}0.592^{\mathrm{a}} \\
(0.523,0.670)\end{array}$ & $\begin{array}{c}0.698^{a} \\
(0.656,0.743)\end{array}$ & $\begin{array}{c}0.651^{\mathrm{a}} \\
(0.586,0.724)\end{array}$ & $\begin{array}{c}1.012 \\
(0.908,1.128)\end{array}$ & $\begin{array}{c}0.949 \\
(0.888,1.013)\end{array}$ & $\begin{array}{c}0.927 \\
(0.845,1.018)\end{array}$ \\
\hline $\begin{array}{l}\text { Model 4: Complete initiation + number of } \\
\text { orders + age + sex + DxRx PM score + PS weighting }\end{array}$ & $\begin{array}{c}0.783^{\mathrm{a}} \\
(0.680,0.902)\end{array}$ & $\begin{array}{c}0.766^{\mathrm{a}} \\
(0.717,0.818)\end{array}$ & $\begin{array}{c}0.766^{\mathrm{a}} \\
(0.679,0.864)\end{array}$ & $\begin{array}{c}1.001 \\
(0.892,1.125)\end{array}$ & $\begin{array}{c}0.928^{b} \\
(0.868,0.993)\end{array}$ & $\begin{array}{c}0.908 \\
(0.822,1.004)\end{array}$ \\
\hline
\end{tabular}

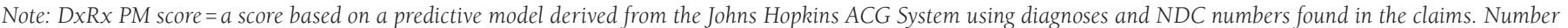
of orders = number of first-ordered e-prescriptions derived from the EHR during the year.

aP $<0.01$.

${ }^{b} P<0.05$.

ACG = Adjusted Clinical Group; $C I=$ confidence interval; ED=emergency department; EHR=electronic health record; IP =inpatient; NDC =National Drug Code; PS = propensity score.

Because of these notable differences in underlying characteristics between the 2 groups, we used propensity score weighting to control confounding rather than simply including control variables in regression models, as has been done in a number of past studies. ${ }^{6,7,12,14,16}$ In addition, the number of first-order prescribed medications was also contained as a covariate in the propensity score and outcome regression models in this study.

Consistent with past studies, ${ }^{5-9}$ our study showed that the medication nonadherence (as defined by complete medication initiation) was associated with higher medical costs and a higher likelihood of having an ED visit (Table 2 and Table 3). However, our study showed a nonstatistically significant association of prescription filling status and pharmacy costs despite that previous studies have shown lower pharmacy costs among patients with complete medication initiations. ${ }^{6.9}$ The inconclusive variability of pharmacy costs between our study's subpopulations with complete and incomplete medication initiations might have originated from the tradeoff between fewer medications to pay initially but higher morbidity levels in the long term. Further research is necessary to clarify the temporal association of pharmacy costs and prescription filling status.

In our study, the magnitude of the change in cost associated with complete medication initiations was lower compared with past studies. ${ }^{5-7}$ The lower levels of the change in cost might be due to the following reasons:

1. We employed propensity score weighting to control for confounding, while healthy adherer bias was not controlled in past studies. ${ }^{6,10}$ Indeed, if baseline differences (e.g., lower morbidity burden among people with complete medication initiations) were not properly adjusted for, the results would overestimate the possible savings from medication adherence, as shown in 1 study comparing the health care savings before and after taking into account the healthy adherer effect. ${ }^{10}$

2. We used EHR data to calculate the number of prescribed orders, while past studies relied solely on claims data to calculate adherence and, as a result, missing prescribed orders that were never filled. As mentioned earlier, patients with incomplete medication initiations had higher numbers of prescribed orders by nature. If we excluded the number of prescribed orders from the models without the ATT weighting (i.e., models 1 and 3; the ATT weighting included the number of prescribed orders in its calculation), the magnitude of the change in cost would have increased dramatically (e.g., model 3 would have shown a savings of $\$ 2,304 / \$ 534$, instead of $\$ 827 / \$ 74$, for concurrent/prospective total costs associated with medication full initial fillers; Table 2).

3. Our study examined the general population of a health system without restricting it to a specific medical condition. Given that the general population of a health system may contain relatively healthy people without any specific disease (e.g., annual checkup encounters), their health care consumption would be much lower than those with a specific medical condition, so the possible cost saving would be lower.

Recent studies have explored the use and added value of EHR data in advancing risk stratification analytics that traditionally use claims data for training and validation. ${ }^{17,18,20,27,38}$ These studies are particularly important for the efforts of health care providers contracting value-based payment models and, as a result, trying to achieve efficient population health management using their own EHR data. ${ }^{39-41}$ Our study adds to the growing body of literature on EHR-derived risk stratification by providing a pragmatic measure (complete vs. incomplete medication initiations, instead of a more complex adherence 
rate such as PMN) that uses EHR data for improving risk adjustment models that explain utilization (e.g., hospitalization and ED admission; Table 3).

\section{Limitations}

There are several limitations in our study. First, the study sample came from 1 health care plan, and the older adult population was excluded because of the lack of complete Medicare claims, thus, the results should be applied to other populations with caution.

Second, the calculation of medication filling was based on a broad ACG-based medication classification system (RxMGs), which may have led to the overestimation of medication filling rates and the number of complete medication initiations. Thus, the results of cost reduction in our study may be underestimated, since some "actual" incomplete medication initiations may be classified as complete initiations.

Third, although we had adopted a reliable method to control for confounding in the observational studies (i.e., propensity score weighting) and included multiple variables in constructing ATT weighting, residual confounding may still exist. For example, there are other factors that may be included in the propensity score model, such as cost of medications and brand versus generic composition of medications.

Fourth, we did not evaluate physical or cognitive limitations and potentially nonmedical factors of affordability and accessibility while evaluating the health care costs and utilization associated with complete medication initiations (mainly to keep it a pragmatic measure for population health management efforts).

Fifth, we only know whether patients filled the prescription from claims data but could not be sure whether those medications were actually taken.

Finally, we did not distinguish acute medications from chronic ones, but the effect of the filling rate between these 2 may be different. Future studies should focus on these limitations and expand on the applicability of medication initiations as a measure of adherence for population health management purposes.

\section{Conclusions}

$\overline{\text { Our study results indicate that having complete medication }}$ initiations was associated with lower total and medical costs, concurrently and prospectively. In addition, having complete medication initiations was associated with lower likelihood of health care utilization concurrently and lower likelihood of having any ED visits prospectively. The medication initiation measure, a simple binary marker, can enable population health management programs-especially programs administered by health care providers that have access to both EHR and claims data-to advance targeting their population-level interventions toward subpopulations (e.g., patients with incomplete medication initiations) that can bring the highest savings.

\section{Authors}

HSIEN-YEN CHANG, PhD, and HONG J. KAN, PhD, Center for Population Health IT, Department of Health Policy and Management, and Center for Drug Safety and Effectiveness, Johns Hopkins Bloomberg School of Public Health, Baltimore, Maryland. KENNETH M. SHERMOCK, PharmD, PhD, Center for Drug Safety and Effectiveness and Department of Epidemiology, Johns Hopkins Bloomberg School of Public Health, Baltimore, Maryland, and Center for Medication Quality and Outcome, Johns Hopkins Hospital, Baltimore, Maryland. G. CALEB ALEXANDER, MD, MSC, Center for Drug Safety and Effectiveness and Department of Epidemiology, Johns Hopkins Bloomberg School of Public Health, Baltimore, Maryland. JONATHAN P. WEINER, DrPh, Center for Population Health IT and Department of Health Policy and Management, Johns Hopkins Bloomberg School of Public Health, Baltimore, Maryland. HADI KHARRAZI, MD, PhD, Center for Population Health IT and Department of Health Policy and Management, Johns Hopkins Bloomberg School of Public Health, Baltimore, Maryland, and Division of Health Sciences and Informatics, Johns Hopkins School of Medicine, Baltimore, Maryland.

CORRESPONDING AUTHOR: Hsien-Yen Chang, PhD, Associate Scientist, Johns Hopkins Bloomberg School of Public Health, 624 N. Broadway, \#682, Baltimore, MD 21205. Tel.: 410.614.5812; Email: hchang24@jhmi.edu.

\section{DISCLOSURES}

No outside funding supported this study. This study applied the Adjusted Clinical Group (ACG) case-mix/risk adjustment methodology, developed at Johns Hopkins Bloomberg School of Public Health. Although ACGs are an important aspect of this study, the goal of the study was not to directly assess or evaluate the methodology. The Johns Hopkins University receives royalties for nonacademic use of software based on the ACG methodology. Chang, Kharrazi, and Weiner receive a portion of their salary support from this revenue

Chang is also a part-time consultant for Monument Analytics, a health care consultancy whose clients include the life sciences industry, as well as plaintiffs in opioid litigation. Alexander is past Chair of FDA's Peripheral and Central Nervous System Advisory Committee; has served as a paid advisor to IQVIA; is a co-founding Principal and equity holder in Monument Analytics; and is a member of OptumRx's National P\&T Committee. These arrangements have been reviewed and approved by Johns Hopkins University in accordance with its conflict of interest policies. The other authors have nothing to disclose.

\section{ACKNOWLEDGMENTS}

The authors acknowledge the support of HealthPartners (Bloomington, $\mathrm{MN}$ ) in sharing the underlying data and Mrs. Susan M. Knudson (Health Informatics) and Mr. Jason M. Gallagher (Health Informatics) for providing the research team with technical support throughout the research.

\section{DATA STATEMENT}

The data that support the findings of this study are available from HealthPartners but restrictions apply to the availability of these data, which were used under license for the current study and so are not publicly available. The data are, however, available from the authors upon reasonable request and with permission of HealthPartners. 


\section{Integrating E-Prescribing and Pharmacy Claims Data for Predictive Modeling: Comparing Costs and Utilization of Health Plan Members Who Fill Their Initial Medications with Those Who Do Not}

\section{REFERENCES}

1. World Health Organization. Adherence to Long-Term Therapies: Evidence for Action. Geneva: World Health Organization; 2003.

2. Chisholm-Burns MA, Spivey CA. The 'cost' of medication nonadherence: consequences we cannot afford to accept. J Am Pharm Assoc (2003). 2012;52(6):823-26

3. Viswanathan M, Golin CE, Jones CD, et al. Interventions to improve adherence to self-administered medications for chronic diseases in the United States: a systematic review. Ann Intern Med. 2012;157(11):785-95. 4. Watanabe JH, McInnis T, Hirsch JD. Cost of prescription drug-related morbidity and mortality. Ann Pharmacother. 2018;52(9):829-37.

5. Quittner AL, Zhang J, Marynchenko M, et al. Pulmonary medication adherence and health-care use in cystic fibrosis. Chest. 2014;146(1):142-51

6. Bitton A, Choudhry NK, Matlin OS, Swanton K, Shrank WH. The impact of medication adherence on coronary artery disease costs and outcomes: a systematic review. Am J Med. 2013;126(4):357.e7-357.e27.

7. Egede LE, Gebregziabher M, Dismuke CE, et al. Medication nonadherence in diabetes: longitudinal effects on costs and potential cost savings from improvement. Diabetes Care. 2012;35(12):2533-39.

8. Capoccia K, Odegard PS, Letassy N. Medication adherence with diabetes medication: a systematic review of the literature. Diabetes Educ. 2016;42(1):34-71

9. De Vera MA, Mailman J, Galo JS. Economics of non-adherence to biologic therapies in rheumatoid arthritis. Curr Rheumatol Rep. 2014;16(11):460.

10. Stuart BC, Dai M, Xu J, Loh FH, J SD. Does good medication adherence really save payers money? Med Care. 2015;53(6):517-23.

11. Mikyas Y, Agodoa I, Yurgin N. A systematic review of osteoporosis medication adherence and osteoporosis-related fracture costs in men. Appl Health Econ Health Policy. 2014;12(3):267-77.

12. Lee A, Song X, Khan I, et al. Association of cinacalcet adherence and costs in patients on dialysis. J Med Econ. 2011;14(6):798-804.

13. Suehs BT, Davis C, Galaznik A, Joshi AV, Zou KH, Patel NC. Association of out-of-pocket pharmacy costs with adherence to varenicline. J Manag Care Spec Pharm. 2014;20(6):592-600. Available at: https://www.jmcp.org/ doi/10.18553/jmcp.2014.20.6.592.

14. Kleinman NL, Odell K, Chen CI, Atkinson A, Zou KH. Persistence and adherence with urinary antispasmodic medications among employees and the impact of adherence on costs and absenteeism. J Manag Care Spec Pharm. 2014;20(10):1047-56. Available at: https://www.jmcp.org/doi/10.18553/ jmcp.2014.20.6.592

15. Lopert R, Shoemaker JS, Davidoff A, et al. Medication adherence and Medicare expenditure among beneficiaries with heart failure. Am J Manag Care. 2012;18(9):556-63

16. Li YC, Huang WL. Effects of adherence to statin therapy on health care outcomes and utilizations in Taiwan: a population-based study. Biomed Res Int. 2015;2015:149573

17. Chang HY, Richards TM, Shermock KM, et al. Evaluating the impact of prescription fill rates on risk stratification model performance. Med Care. 2017:55(12):1052-60

18. Kharrazi H, Chi W, Chang HY, et al. Comparing population-based risk-stratification model performance using demographic, diagnosis and medication data extracted from outpatient electronic health records versus administrative claims. Med Care. 2017;55(8):789-96

19. De Geest S, Zullig LL, Dunbar-Jacob J, et al. ESPACOMP Medication Adherence Reporting Guideline (EMERGE). Ann Intern Med. 2018;169(1):30-35.

20. Kharrazi H, Chang HY, Heins SE, Weiner JP, Gudzune KA. Assessing the impact of body mass index information on the performance of risk adjustment models in predicting health care costs and utilization. Med Care 2018:56(12):1042-50
21. Forrest CB, Lemke KW, Bodycombe DP, Weiner JP. Medication, diagnostic, and cost information as predictors of high-risk patients in need of care management. Am J Manag Care. 2009;15(1):41-48.

22. Weiner JP, Starfield BH, Steinwachs DM, Mumford LM. Development and application of a population-oriented measure of ambulatory care casemix. Med Care. 1991;29(5):452-72

23. Starfield B, Weiner J, Mumford L, Steinwachs D. Ambulatory care groups: a categorization of diagnoses for research and management. Health Serv Res. 1991;26(1):53-74

24. Chang HY, Bodycombe DP, Huang WF, Weiner JP. Risk-adjusted resource allocation: using Taiwan's National Health Insurance as an example. Asia Pac J Public Health. 2015;27(2):NP958-NP971.

25. Chang HY, Weiner JP. An in-depth assessment of a diagnosis-based risk adjustment model based on national health insurance claims: the application of the Johns Hopkins Adjusted Clinical Group case-mix system in Taiwan. BMC Med. 2010;8:7.

26. Corti MC, Avossa F, Schievano E, et al. A case-mix classification system for explaining healthcare costs using administrative data in Italy. Eur J Intern Med. 2018;54:13-16.

27. Kan HJ, Kharrazi H, Leff B, et al. Defining and assessing geriatric risk factors and associated health care utilization among older adults using claims and electronic health records. Med Care. 2018;56(3):233-39.

28. Chang HY, Clark JM, Weiner JP. Morbidity trajectories as predictors of utilization: multi-year disease patterns in Taiwan's national health insurance program. Med Care. 2011;49(10):918-23.

29. Chang HY. The impact of morbidity trajectories on identifying high-cost cases: using Taiwan's National Health Insurance as an example. J Public Health (Oxf). 2014;36(2):300-07.

30. Chang HY, Lee WC, Weiner JP. Comparison of alternative risk adjustment measures for predictive modeling: high risk patient case finding using Taiwan's National Health Insurance claims. BMC Health Serv Res. 2010;10:343

31. Chang HY, Boyd CM, Leff B, Lemke KW, Bodycombe DP, Weiner JP. Identifying consistent high-cost users in a health plan: comparison of alternative prediction models. Med Care. 2016;54(9):852-59.

32. Reid RJ, Roos NP, MacWilliam L, Frohlich N, Black C. Assessing population health care need using a claims-based ACG morbidity measure: a validation analysis in the Province of Manitoba. Health Serv Res. 2002;37(5):1345-64.

33. Chang HY, Hsieh CF, Singh S, Tang W, Chiang YT, Huang WF. Anti-diabetic therapies and the risk of acute pancreatitis: a nationwide retrospective cohort study from Taiwan. Pharmacoepidemiol Drug Saf. 2015;24(6):567-75.

34. Chang HY, Zhou M, Tang W, Alexander GC, Singh S. Risk of gastrointestinal bleeding associated with oral anticoagulants: population based retrospective cohort study. BMJ. 2015;350:h1585.

35. Tung YC, Chang GM, Chang HY, Yu TH. Relationship between early physician follow-up and 30-day readmission after acute myocardial infarction and heart failure. PLoS One. 2017;12(1):e0170061.

36. Austin PC. An introduction to propensity score methods for reducing the effects of confounding in observational studies. Multivariate Behav Res. 2011;46(3):399-424

37. Shen Y, Ellis RP. How profitable is risk selection? A comparison of four risk adjustment models. Health Econ. 2002;11(2):165-74.

38. Lemke KW, Gudzune KA, Kharrazi H, Weiner JP. Assessing markers from ambulatory laboratory tests for predicting high-risk patients. Am J Manag Care. 2018;24(6):e190-e195.

39. Hatef E, Kharrazi H, VanBaak E, et al. A state-wide health IT infrastructure for population health: building a community-wide electronic platform for Maryland's all-payer global budget. Online J Public Health Inform. 2017:9(3):e195. 
Integrating E-Prescribing and Pharmacy Claims Data for Predictive Modeling:

Comparing Costs and Utilization of Health Plan Members Who Fill Their Initial Medications with Those Who Do Not

40. Kharrazi H, Lasser EC, Yasnoff WA, et al. A proposed national research and development agenda for population health informatics: summary

recommendations from a national expert workshop. J Am Med Inform Assoc. 2017;24(1):2-12.
41. Hatef E, Lasser EC, Kharrazi HHK, Perman C, Montgomery R, Weiner JP. A population health measurement framework: evidence-based metrics for assessing community-level population health in the global budget context. Popul Health Manag. 2018;21(4):261-70. 